\title{
Use of fuzzy systems in the elaboration of an anthropic pressure indicator to evaluate the remaining forest fragments
}

\author{
R. W. Lourenço • D. C. C. Silva • A. C. G. Martins • \\ J. C. A. Sales - S. R. M. M. Roveda • \\ J. A. F. Roveda
}

Received: 30 June 2014 / Accepted: 1 March 2015/Published online: 7 March 2015

(C) Springer-Verlag Berlin Heidelberg 2015

\begin{abstract}
The aim of the present paper is to develop a spatial analysis methodology with an inference fuzzy system using the geoprocessing techniques to generate an anthropic pressure indicator (API) based on two other indicators: Circularity Index (CI) and Edge Effects Index (EEI). This new methodology could indicate the remaining forest fragments exposition level after the anthropic action, considering the relationship between the geometry (CI) and the type of land use around the area (EEI) as the main factors. The studied area is located in the southwest part of São Paulo state, Brazil. The obtained results show that rivers are often found as limits between fragments, demonstrating the importance of the preservation and conservation of riparian forest. In total, 846 forest fragments were identified, occupying $6.19 \%$ of the study area, totalizing 2775.7 ha. Out of the total fragments $48.7 \%$ were in medium and advanced successional stage of
\end{abstract}

\footnotetext{
R. W. Lourenço $(\bowtie)$ D D. C. C. Silva · A. C. G. Martins ·

J. C. A. Sales - S. R. M. M. Roveda - J. A. F. Roveda

Environmental Engineering, UNESP - Univ Estadual Paulista,

Campus de Sorocaba, Avenida Três de Março, 511, Sorocaba,

São Paulo 18087-180, Brazil

e-mail: robertow@sorocaba.unesp.br

D. C. C. Silva

e-mail: darllanamb@yahoo.com.br

A. C. G. Martins

e-mail: amartins@ sorocaba.unesp.br

J. C. A. Sales

e-mail: jomilc@gmail.com

S. R. M. M. Roveda

e-mail: sandra@sorocaba.unesp.br

J. A. F. Roveda

e-mail: roveda@sorocaba.unesp.br
}

regeneration presenting elongated shapes and $16 \%$ were in a high fragility interval, consequence of the edge effects. Moreover, the map of API showed that $16.2 \%$ forest fragments were in a moderate high anthropic pressure interval, which deserve special attention for being very elongated, limited and pressured in an intense way by different types of land use which affect its surroundings. Thereby, the study demonstrated that the understanding of pressure types imposed on the remaining forest fragments through an indicator can contribute to management programs and territorial planning, giving conditions to the forest restoration in areas of strong anthropic pressure, and that the employment of fuzzy logics and geoprocessing could contribute significantly to diagnosis and trouble characterizations.

Keywords Inference fuzzy system - Anthropic pressure indicator $\cdot$ Remaining forest fragments $\cdot$ Geoprocessing

\section{Introduction}

The fragmentation of the remaining forests is considered one of the most severe threats to biological diversity of the forests, which is mainly caused by man.

The majority of the remaining forests, located close to urban centers, are isolated in small fragments, which in the last decades have been degraded due to soil use and occupation. These fragments consist mainly of secondary forests or forests in medium stage of ecological succession (Metzger 2000; Liu et al. 2011).

From an ecological point of view and due to large resilience potential, the forest fragments in advanced and medium stage of ecological succession are the most representative of the Atlantic forest. Moreover, the fragments 
known as pioneer stage are in a fragile regeneration phase, susceptible to anthropic actions. The primary stage is located in the climax of succession, known by the biggest biodiversity and by the balance of pioneer and secondary species of plants beyond the wildlife (Ranta et al. 1998).

Nowadays, landscape ecology is a consolidated multidisciplinary science. One of the landscape ecology goals is to help solving some of the main contemporary environmental challenges in biologic diversity conservation, based on the hypothesis that the interactions between the biotic and abiotic components are especially measurable (Marenzi and Gerhardinger 2006).

According to Vidal et al. (2007) and Teixeira et al. (2009), when helping to understand the complex structure of the landscape and the influence in ecological relations, the quantitative measures of the landscape composition, known as metrics or landscape indicators, are getting more and more attention.

This way, studies on how the use and management of the soil determine the shape, the type, the intensity and the frequency in which occurs the remaining forest fragmentation-resulting from deforestation of its surroundingshave become of relevant environmental importance. Studies of this nature help to understand which types of use and management alter more significantly the pattern and ecological stability. They can also contribute to the elaboration of conservationist practices and of forest preservation that favor the management and protection of these resources in an efficient and sustainable way (Echeverría et al. 2006; Nemésio and Silveira 2010).

In this context, the creation of an indicator, which can be easily calculated and clearly expresses the complexity of the analysis of the anthropic pressure over the fragments, in medium and advanced stage of succession, is of fundamental importance to subsidize the government agencies to make decisions (Vidal et al. 2007; Teixeira et al. 2009). On the other hand, indicators are susceptible to questionings due to the subjectivities that are associated with weighting of the parameters and the imprecision associated with measuring area, perimeter and shape.

In recent years, the fuzzy set theory, introduced by Zadeh (1965), has been used to classify and quantify several environment effects. Silvert (2000) underscores the fact that this theory provides a useful approach to the development of environmental indices. The goal of the fuzzy sets is a conceptual framework suitable for the treatment of problems possessing intrinsic subjectivity (Pradhan 2011).

Some studies with fuzzy sets and geoprocessing have been developed for different purposes. Lourenço et al. (2010) used geoprocessing techniques to map soil pollution using fuzzy inference system. Uricchio et al. (2004) and Di Martino et al. (2005) used geoprocessing techniques to map an aquifer in a municipality area of Italy, using hierarchical fuzzy techniques. Mizumoto (1982) and Afshar et al. (2007) used a fuzzy inference system to propose an indicator of fuzzy vulnerability for groundwater, from a group of rules composed by input variables, categorized in different degrees, as "low", "medium" and "high".

This way, the combined use of geoprocessing tools and fuzzy systems to analyze the land use of forest fragment surroundings, as well as their metric shape, permit to evaluate the fragmentation and degradation risk to which they are exposed, and it can subsidize management and constant inspection measures at the sites mostly vulnerable (Zipperer 1993; Echeverría et al. 2006; Nemésio and Silveira 2010).

Thus, this work proposes the elaboration of a methodology integrating the fuzzy inference system with the use of the geoprocessing techniques to generate an anthropic pressure indicator (API) which could be able to reflect the exposition levels of the remaining forest fragments under anthropic action, once the relationship between Circularity Index (CI) and the Edge Effects Index (EEI) is considered as the main factor of intervention.

\section{Methodology}

\section{Study area}

Fragments of the remaining forest in advanced and medium successional stage used in this proposed methodology are located in Sorocaba, in São Paulo State, Brazil (Fig. 1), one of the main emergent cities of the southwest region of the state of São Paulo, with substantial industrial concentration and agricultural expansion, causing strong environmental impacts. Thus, there is a huge need to preserve the existing forest remnants in the city.

\section{Land use mapping}

Satellite images of the sensor orbital TM/Landsat-5 of orbit point 220/76 from the year 2013 were used for the soil use and vegetal coverage mapping. From these images RGB compositions were performed, respectively, from red, green and blue bands for the classification of predominant anthropic uses and band composition of near infrared, medium infrared and red for the classification of vegetation and hydric bodies. The classification was performed with the multivariate supervised classification method of maximum likelihood available at ArcGis 10.1 (ESRI 2012).

The types of use were classified as follows: pasture, exposed soil, agriculture, residential, industrial, hydrographic and forests. The forests were reclassified according to their successional stage and photo interpretation techniques were used in aerial photos at 1:8000 scale granted 


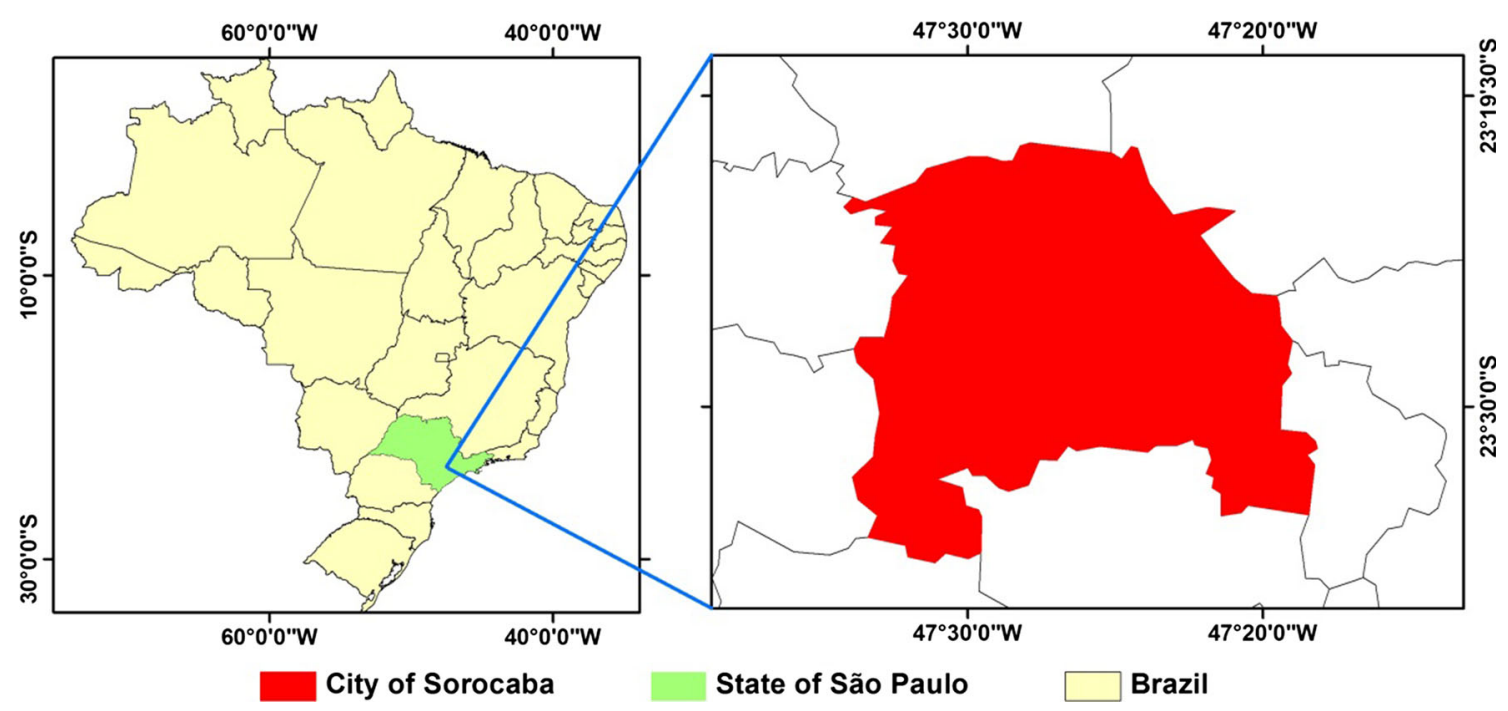

Fig. 1 Study area

by Sorocaba City Hall in 2012. Besides, some field visits were performed to validate successional stage classification of vegetation and the soil use classes.

CI calculation

The CI was calculated from the geometric shape analysis of each of the remaining forest fragments in the study area, considering the circularity characteristics and extension of each analyzed fragment (Viana and Pinheiro 1998), according to Eq. (1):

$\mathrm{CI}=\frac{2 \sqrt{\pi A}}{P}$,

where CI is Circularity Index; $A$, area of the fragment; $P$, perimeter of the fragment.

The values of the area and of the perimeter were calculated in columns added to the attribute table of the digital map of fragments through the tool calculate geometrylpropertylarea or perimeter. Next, another column was added to the same table and implemented the Eq. 1 using the tool field calculator, generating the $\mathrm{CI}$ amount for each one of the existing fragments. This step was performed at ArcGis 10.1.

The values of CI lie within the interval between 0 and 1 , considering that the values which approach to 1 indicate fragments with a tendency for circular shape, and when these values become smaller, the fragment presents more elongated shape.

According to Viana and Pinheiro (1998), when this index is smaller than 0.6 the fragments are considered "very elongated"; between 0.6 and 0.8 "elongated"; and bigger than 0.8 "rounded". Consequently, fragments that are very elongated are more susceptible to the edge effects that are harmful to the conservation of the remaining forests.

From the classes defined by Viana and Pinheiro (1998), linguistic variables from $\mathrm{CI}$ were established, in which "Low" CI is defined as a fragment with low vulnerability to the effects of the edge, "Medium" CI as a fragment of the medium vulnerability and "High" CI as a fragment with high vulnerability, therefore, more vulnerable to degradation risk.

\section{EEI calculation}

The EEI determines the fragility level that the remaining forest fragments are exposed to, considering the anthropic activities in the immediate surroundings. Low values of EEI indicate fragmentation that leads to habitat reduction and loss of local species due to increased isolation of the remaining forest fragments (Laurance and Yensen 1991; Barrera 2004; Feng et al. 2011).

Each fragment was analyzed regarding the edge effect caused by the direct neighborhood, considering four groups of land use: exposed soil, pasture, urban/commercial/industrial edifications and areas of agriculture. Pasture and/or exposed soil are of lesser restriction, as they allow the expansion of the fragments. In relation to the urban/commercial/industrial edifications and areas of agriculture, in addition to the physical barrier imposition, they can damage the adjacent fragments due to pollution generation. These four land uses were assigned different weights, according to the damage level that can be imposed to the fragments, and the weights are in inverse proportion to their value, i.e., higher damage value equals 0.00 and lower damage value equals 1.00 (Table 1). 
Table 1 Attributed weights to each land use

\begin{tabular}{lc}
\hline Land uses & Values \\
\hline Exposed soil & 1.00 \\
Pasture & 0.70 \\
Residential & 0.35 \\
Industrial and agricultural & 0.00 \\
\hline
\end{tabular}

From these weights the EEI was built as the sum of the weighted uses by the neighborhood perimeter of each land use with the remaining forest fragments normalized 1 as shown in Eq. (2):

$\mathrm{EEI}=\sum_{i=1}^{4} \frac{U_{i} \times P_{i}}{P}$

where EEI is the Edge Effects Index; $U_{i}$ weight value attributed to the type of land use; $P_{i}$ perimeter boundary of land use with the fragment; $P$, total perimeter of the fragment.

The EEI values were classified according to the restriction level presented on Table 1 and as follows: low fragility (Low), representing fragments mainly surrounded by exposed soils and pasture standing for the fragments with value above $85 \%$ of EEI; medium fragility (Medium), representing fragments mainly surrounded by pasture with less existence of exposed soil, urban and agricultural buildings standing for the fragments with value between 45 and $85 \%$; high fragility (High), representing fragments mainly surrounded by urban, commercial, industrial buildings or agricultural areas with low occurrence of pasture and exposed soil, standing for the fragments with EEI value lower than $45 \%$.

For EEI quantification, the buffer tool present at ArcToolbox of ArcGis 10.1 was used for the calculation of a radius of $0.01 \mathrm{~m}$ from each fragment; then their perimeter was quantified and weight attributed (Table 1) to each one of the types of soil use identified. Next, the EEI value for each one of the types of soil use was individually calculated at the field calculator, present at the attribute table, and from this, solving tool present at ArcToolbox was used to add EEI individual values and thus the final EEI value was obtained for each one of the fragments.

\section{API calculation}

The API was elaborated based on the fuzzy inference system using the Circularity Index (CI) and the EEI to build the pertinence functions using the module Fuzzy Logic Toolbox of Matlab R2010a (The MathWorks 2014).

Figure 2 shows the fuzzy sets that have been classified linguistically by the terms Maximum, Moderate High, Moderate, Moderate Low and Minimum. (a) Membership functions of the $\mathrm{Cl}$

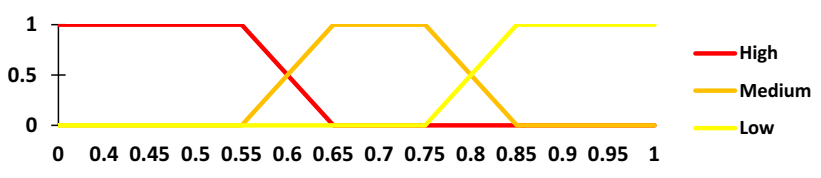

(b) Membership functions of the EEI

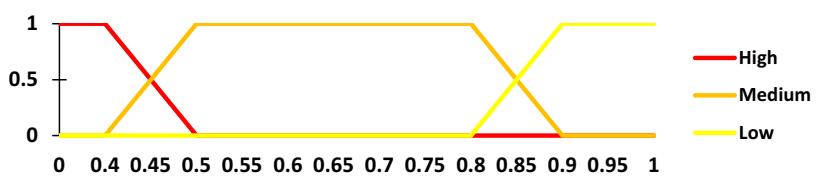

(c) Membership functions of the API

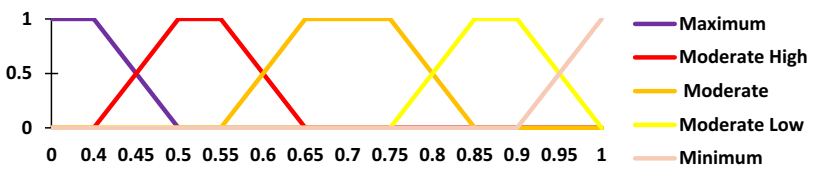

Fig. 2 Input variables and output with membership functions of trapezoidal shape

Table 2 Rule of the model

\begin{tabular}{llll}
\hline Rules & Input & & $\begin{array}{l}\text { Output } \\
\text { API }\end{array}$ \\
\cline { 2 - 3 } & CI & EEI & Maximum \\
\hline 1 & High & High & Moderate high \\
2 & & Medium & \\
3 & & Low & Moderate \\
4 & Medium & High & Maximum \\
5 & & Medium & Moderate high \\
6 & & Low & Moderate \\
7 & Low & High & Moderate \\
8 & & Medium & Moderate low \\
9 & & Low & Minimum \\
\hline
\end{tabular}

The rule bases, shown in Table 2, were defined considering the experts experience. This set of rules and the input and output membership functions were based on Mamdani (1974) inference process.

To obtain a real number to indicate the anthropic pressure by a defuzzification method, the center of gravity according to Ross (2009) was used.

The API proposed was divided into the classes Maximum, Moderate High, Moderate, Moderate Low and Minimum (Fig. 2c) considering the values of the intervals presented by the CI and EEI. Figure 2a, b, except for the Minimum class, which was qualified from values above $95 \%$, presenting the smallest interval of $5 \%$.

The remaining forest fragments of very irregular and elongated shape were qualified as "Maximum" because they present an extremely high anthropic pressure from the external area with the predominance of industrial and agricultural neighborhood. 
The second class, qualified as "Moderate high", is characterized by industrial activities, agricultural, commercial edifications and residences adjacent to the forest fragments and also with predominantly irregular and elongated shapes. In the "Moderate" and "Moderate Low" classes there is a predominance of pasture with more regular and circular shapes, while, the "Minimum" consists of the class with the lowest anthropic pressure on the fragment, with predominance of exposed soil that facilitates the regeneration of the fragment and also presents a circular shape.

The values of CI and EEI, fragment identification and map layout were obtained with GIS ArcGis 10.1; whereas, the fuzzy process was implemented with Matlab R2010a.

\section{Results and discussion}

The remaining forest fragments in the study area with different stages (medium and advanced) are showed in Fig. 3.

In Fig. 3 it is possible to verify that the rivers are constantly present as limits between the fragments. This is

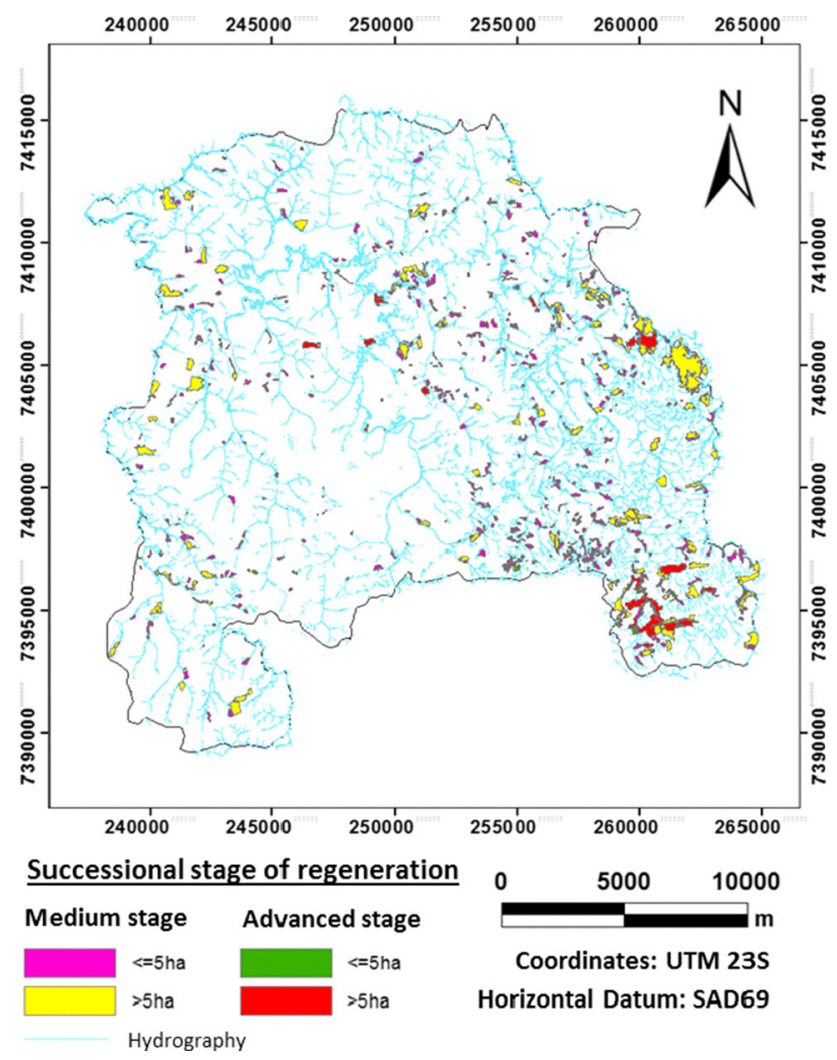

Fig. 3 Location of the remaining forest fragments according to the stages medium and advanced relevant because the current country legislation establishes the mandatory presence of riparian forest along the water courses and the maintenance of these vegetal fragments guarantees the sustainability of the water courses.

In total, 846 fragments of remaining forests in medium and advanced successional stage (2775.7 ha) isolated in the country area were identified, with 320.1 ha in successional advanced stage and 2455.6 ha in medium successional stage. Table 3 presents the area values of the forest remaining fragments in relation to the city area, classified as bigger or smaller than 5 ha.

The 846 fragments from the remaining forests occupy only $6.19 \%$ of the total area, with the majority being concentrated in the east and southwest parts. It was observed, that approximately $47.44 \%$ from the total forest remaining fragments in medium and advanced successional stage from Sorocaba present a characteristic of elongated shape, making them more vulnerable to anthropic activities developed in their surroundings. These values are found proportionally divided between both successional stages of the evaluated vegetation (Table 4).

Table 5 shows the distribution, in percentage, of the EEI values for three classes of anthropic pressure (low, medium and high fragility).

The value of the EEI alone represents the contribution of the surrounding landscapes to the development or to the stagnation and even to the disappearance of the fragments. Approximately $84 \%$ of the fragments in advanced and medium successional stage presented in Table 5 are found in the range of Medium Fragility characterizing regeneration conditions and maintenance of the environmental quality. However, about $16 \%$ of the fragments in advanced and medium successional stage are found in the range of High Fragility, which are limited and intensively exposed to different types of land uses affecting their surroundings and limiting their growth and change into successional stage.

Figure 4 shows the map of Anthropic Pressure Index for the analyzed remaining forest fragments from the city of Sorocaba, as well as the percentage of fragments of the vegetation obtained in each class (maximum, moderate high, moderate, moderate low and minimum anthropic pressure).

The API map shows that $11.2 \%$ of the fragments obtained values in the range of moderate to minimum anthropic pressure, demonstrating that these fragments suffer small pressure from the surrounding land uses, while $72.6 \%$ presented values in the range of moderate high anthropic pressure and $16.2 \%$ are in the maximum anthropic pressure range, which, deserves special attention because they are limited and intensely pressured by different types of land uses that affect the surroundings, limiting their change to successional 
Table 3 Data fragments vegetation in advanced and medium successional stage

\begin{tabular}{lcclll}
\hline & \multicolumn{2}{l}{ Successional stage } & & \multicolumn{2}{l}{ No. of fragments } \\
\cline { 2 - 3 } & Advanced (ha) & Medium (ha) & & Advanced & Medium \\
\hline Total area & 320.1 & 2455.6 & & 50 & 796 \\
Areas smaller or equal to 5 ha & 30.2 & 888.6 & & 33 & 692 \\
Areas bigger than 5 ha & 289.9 & 1567 & & 17 & 104 \\
$\%$ of the fragment area in the municipality & 0.71 & 5.48 & &
\end{tabular}

Table 4 Values of CI for the advanced and medium successional stages

\begin{tabular}{lcll}
\hline Circularity index & Low (\%) & Medium (\%) & High (\%) \\
\hline Advanced successional stage & 6.02 & 47.97 & 46.01 \\
Medium successional stage & 14.07 & 37.06 & 48.87 \\
\hline
\end{tabular}

Table 5 Values of EEI for the advanced and medium successional stages

\begin{tabular}{llll}
\hline Circularity index & Low (\%) & Medium (\%) & High (\%) \\
\hline Advanced successional stage & 0 & 84 & 16 \\
Medium successional stage & 0.88 & 83.29 & 15.83 \\
\hline
\end{tabular}

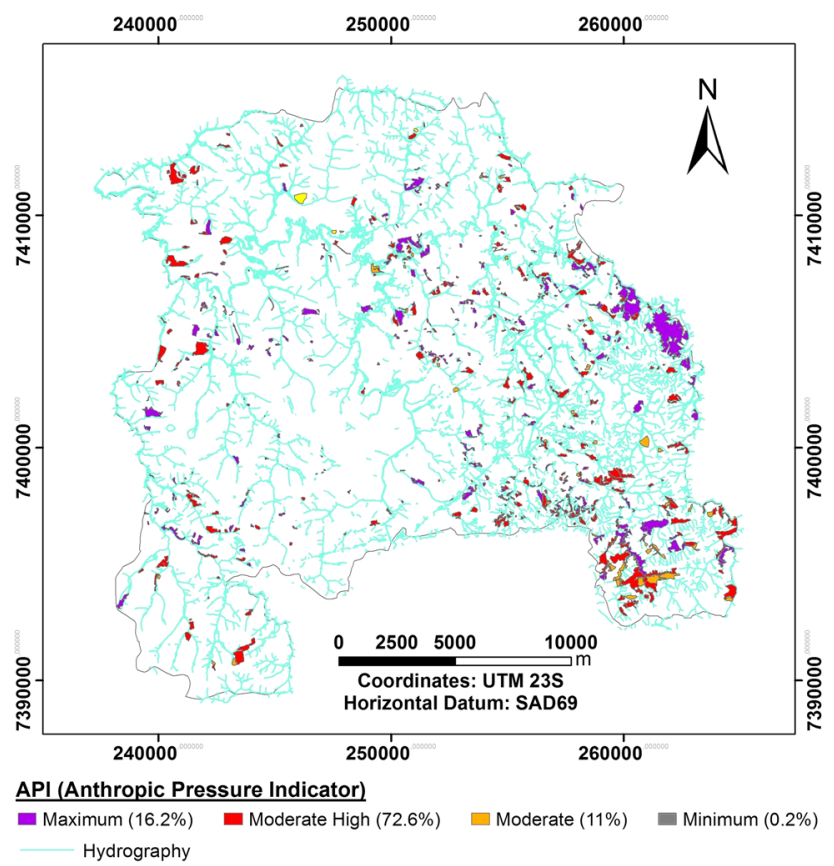

Fig. 4 API of forest fragments in advanced and medium successional stages

stages, formation of ecological corridors and consequently its maintenance. It should be highlighted that there was no value included in the range of moderate low anthropic pressure.
Figure 5 shows a fragment with API value for the maximum anthropic pressure range in an image (aerial photo) where it is possible to observe in the surroundings of the fragment the strong presence of an industrial area, in addition to the strong irregularity on the shape of the fragment, which tends to be more elongated than circular. Such features certainly influenced the API value attributed to this fragment.

The fragments that presented API class values of maximum and moderate anthropic high pressure are mostly remaining forest fragments of the biggest areas (see Fig. 4) and with lower EEI values. Based on that we can conclude that in these cases the bigger the area and perimeter, higher is the occurrence of high pressure anthropic activities, such as, agriculture, housing and industries.

Therefore, these areas presented significant vulnerability, and consequently need more protection for their preservation once the activities developed on their surroundings can suppress the vegetation over time, turning them into smaller dimension fragments.

Among the ten biggest fragments (with areas bigger than 25 ha), $50 \%$ present API classification at maximum, while the other $50 \%$ present API classification at high moderate and are located at the eastern and southeastern region of the study area. These regions are characterized by intense hydrographic network of important springs that supply water for the local population, highlighting even more the need of attention.

Besides, this configuration can favor the development of ecological corridors for the maintenance of the biodiversity and also decrease the fragment vulnerability in relation to anthropic activities developed on its surroundings.

It is important to emphasize that a few fragments in the study area were identified inside the classes of lower anthropic pressure, i.e., the study area presents an extremely anthropized reality, with a strong negative impact on the fragments.

Finally, API proved to be efficient at scoring and consequently at identifying fragments that presented the greatest need of protection from the expansion of human activities point of view. 


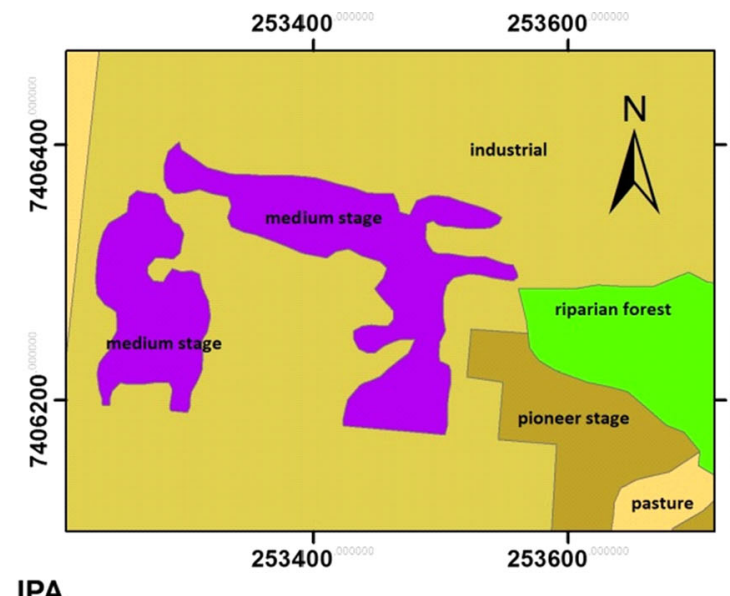

IPA

Maximum Moderate high

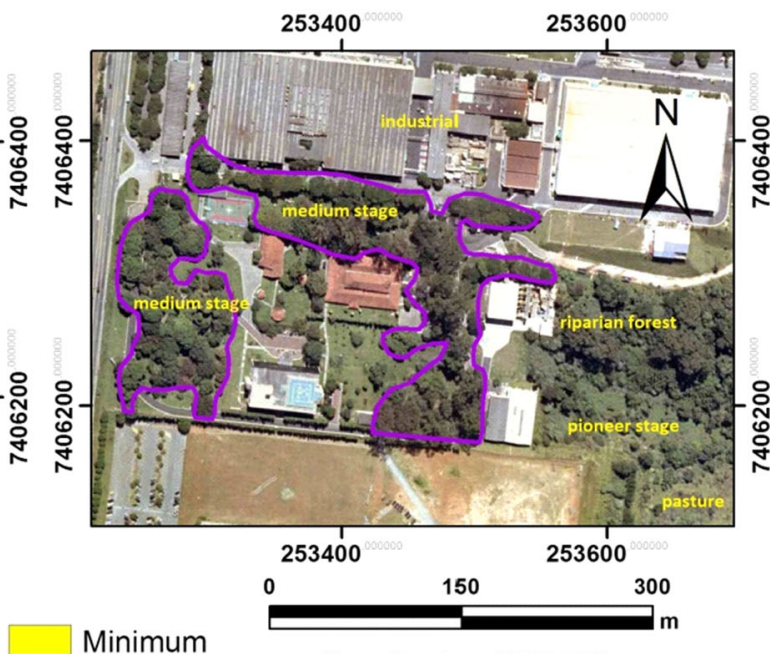

Coordinates: UTM 23S

Horizontal Datum: SAD69

Fig. 5 Forest remaining fragment in medium successional stage with API in the range of maximum anthropic pressure, and the surrounding land use

\section{Conclusion}

The fuzzy techniques associated to geoprocessing methods generated an efficient way to elaborate and construct indicators or indexes, which can be used in controlling and helping decision-making related to the management and planning of the remaining forest areas.

The elaboration of the Anthropic Pressure Index allowed the classification of the forest fragments, from the study area, as in advanced and medium stage of regeneration, and also proved to be an instrument of easy implementation that can be applied to different areas and forest physiognomies. For certain regions, the knowledge base of the EEI can be adjusted, regarding the pertinence degrees, as well as the sets of rules according to regional or local conditions to be studied.

Finally, the results revealed the importance of the elaboration of new public policies for the preservation of the forest environments in cities of medium and large size, as well as the establishment of new specific areas of forest conservation and restoration in degraded areas, benefiting the presence of rivers and riparian areas and, consequently, increasing the connectivity between fragments.

\section{References}

Afshar A, Marino MA, Ebtehaj M, Moosavi J (2007) Rule-based fuzzy system for assessing groundwater vulnerability. J Environ Eng 133(5):532-540. doi:10.1061/(ASCE)0733-9372(2007)133:5(532)

Barrera LF (2004) Estructura y Función en Bordes de Bosques. Ecossistemas 13(1):67-77
Di Martino F, Sessa S, Loia V (2005) A fuzzy-based tool for modelization and analysis of the vulnerability of aquifers: a case study. Int J Approx Reason 38(1):99-111. doi:10.1016/j.ijar. 2004.05.001

Echeverría C, Coomes D, Salas J, Rey-Benayas JM, Lara A, Newton A (2006) Rapid deforestation and fragmentation of Chilean temperate forests. Biol Conserv 130(4):481-494. doi:10.1016/j. biocon.2006.01.017

ESRI (2012) ArcGis 10.1. Copyright $\subset$ ESRI Inc.

Feng Y, Lei LuG, Zhou D, Han Q et al (2011) Effects of land use change on landscape pattern of the Manas River watershed in Xinjiang, China. Environ Earth Sci 64(8):2067-2077. doi:10. 1007/s12665-011-1029-5

Laurance WF, Yensen E (1991) Predicting the impacts of edge effects in fragmented habitats. Biol Conserv 55(1):77-92. doi:10.1016/ 0006-3207(91)90006-U

Liu D, Li B, Liu X, Warrington DN (2011) Monitoring land use change at a small watershed scale on the Loess Plateau, China: applications of landscape metrics, remote sensing and GIS. Environ Earth Sci 64(8):2229-2239. doi:10.1007/s12665-011-1051-7

Lourenço RW, Landim PMB, Rosa AH, Roveda JAF, Martins ACG, Fraceto LF (2010) Mapping soil pollution by spatial analysis and fuzzy classification. Environ Earth Sci 60(3):495-504. doi:10. 1007/s12665-009-0190-6

Mamdani EH (1974) Application of fuzzy algorithms for control of simple dynamic plant. In: Proceedings of the Institution of Electrical Engineers, vol 121(12). IET Digital Library, pp 1585-1588. doi:10.1049/piee.1974.0328

Marenzi RC, Gerhardinger LC (2006) Landscape ecology and effects of habitat fragmentation on biodiversity of coastal environments: case study of Morraria da Praia Vermelha, SC, Brazil. J Coast Res 39:1156-1160

Metzger JP (2000) Tree functional group richness and landscape structure in a Brazilian tropical fragmented landscape. Ecol Appl 10(4):1147-1161. doi:10.2307/2641023

Mizumoto M (1982) Fuzzy conditional inference under max- $\odot$ composition. Inf Sci 27(3):183-209. doi:10.1016/0020-0255(82) 90024-X

Nemésio A, Silveira FA (2010) Forest fragments with larger core areas better sustain diverse orchid bee faunas (Hymenoptera: 
Apidae: Euglossina). Neotrop Entomol 39(4):555-561. doi:10. 1590/S1519-566X2010000400014

Pradhan B (2011) Use of GIS-based fuzzy logic relations and its cross application to produce landslide susceptibility maps in three test areas in Malaysia. Environ Earth Sci 63(2):329-349. doi:10. 1007/s12665-010-0705-1

Ranta P, Blom TOM, Niemela J, Joensuu E, Siitonen M (1998) The fragmented Atlantic rain forest of Brazil: size, shape and distribution of forest fragments. Biodivers Conserv 7(3):385-403. doi:10. 1023/A:1008885813543

Ross TJ (2009) Fuzzy logic with engineering applications. Wiley, New York

Silvert W (2000) Fuzzy indices of environmental conditions. Ecol Model 130(1):111-119. doi:10.1016/S0304-3800(00)00204-0

Teixeira AMG, Soares-Filho BS, Freitas SR, Metzger JP (2009) Modeling landscape dynamics in an Atlantic Rainforest region: implications for conservation. For Ecol Manag 257(4):1219-1230. doi:10.1016/j.foreco.2008.10.011
The MathWorks (2014) Fuzzy Logic Toolbox ${ }^{\mathrm{TM}}$ User's Guide. CCopyright $1995-2014$ by The MathWorks Inc

Uricchio VF, Giordano R, Lopez N (2004) A fuzzy knowledge-based decision support system for groundwater pollution risk evaluation. J Environ Manag 73(3):189-197. doi:10.1016/j.jenvman. 2004.06.011

Viana VM, Pinheiro LAFV (1998) Biodiversity conservation in forest fragments. Tech Ser IPEF 12(32):25-42

Vidal MM, Pivello VR, Meirelles ST, Metzger JP (2007) Litter production in a fragmented Atlantic forest landscape (Ibiúna, SP): the importance of the edge and fragment size. Braz J Bot 30(3):521-532. doi:10.1590/S0100-84042007000300016

Zadeh LA (1965) Fuzzy sets. Inf Control 8(3):338-353. doi:10.1016/ S0019-9958(65)90241-X

Zipperer WC (1993) Deforestation patterns and their effects on forest patches. Landsc Ecol 8(3):177-184. doi:10.1007/BF00125349 